\title{
Summer reading
}

$\mathbf{S}$ ummer has officially arrived-at least for those who live in the northern hemisphere. In addition to the increasing temperature, summer changes the daily routines in our lives. For those with school-age children, it often means shuttling kids back and forth to camps instead of schools. For faculty and graduate students, it usually means a period to focus on research now that the coursework is on hiatus. Summer is also the season for scientific meetings, and many of us are traveling from one place to another. What do you do when you are at a terminal waiting for a flight or a train to depart? Reading is probably the best way to pass the time. While one can certainly read research articles to keep up with the latest scientific developments, a relaxing alternative is to read the biographies of scientists. This summer there are many to choose from.

True to the theme of 'the year of physics', there are many biographies about physicists in 2005 , including more than ten new books on the life, the science and/or the philosophy of Albert Einstein. In addition, there are no less than five books written about Robert Oppenheimer, the

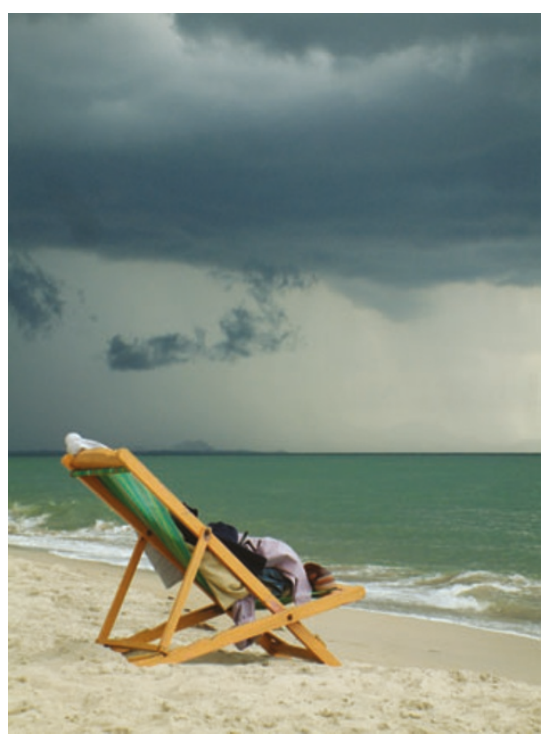

correspondence, revealing his passion to explore and to communicate. The Collected Papers of Albert Einstein, Volume 9 (Princeton University Press) is a compilation of Einstein's letters and documents between January 1919 and April 1920, with extensive comments from the editorial curators, whereas The Born-Einstein Letters 1916-1955 (Macmillan Science) contains 117 letters between Einstein and his friend, the physicist Max Born. The two related books reveal the multidimensionality of Einstein's life and put his work in a historical context.

In contrast to the physicists, the life stories of few biologists and chemists are featured in 2005 . Nevertheless, there are some intriguing choices. Beyond the Outer Shores (Avalon, paperback version published in 2005) is a book about Ed Ricketts, a self-taught ecologist who befriended writer John Steinbeck and was immortalized as the character 'Doc' in Steinbeck's Cannery Row. Splendid Solution (Penguin) is a historical account of the development of the polio vaccine by Jonas Salk and colleagues based on the concept of dead rather than live viruses. This publication commemorates the $50^{\text {th }}$ anniversary of the pronouncement that the Salk vaccine enigmatic scientist who led a team at Los Alamos, New Mexico, in a race against the Nazis to build the first atomic bomb. One of these books, entitled American Prometheus (Knopf), touted as the first full-scale biography of Oppenheimer, describes how Oppenheimer's experiences as a youth in New York shaped his future. The book explores how after Hiroshima he became an advocate for an international control of atomic materials and opposed the development of the hydrogen bomb, and how this opinion was unpopular with the political power of the post World War II era, which led to his loss of security clearance. The book reveals not only Oppenheimer's genius and ambition but also his flaws. The result is a portrait of a complex man that we can admire and relate to.

While the biographies described above allow a glimpse of the person behind the scientific achievements, they are inevitably third-hand narratives reconstructed from documents and interviews. Direct access to some of the greatest scientific minds of the $20^{\text {th }}$ century is now possible through collections of their correspondences. Perfectly Reasonable Deviations from the Beaten Track (Basic Books) is a collection of Richard Feynman's correspondence from 1939 to 1987. The letters, written to family, colleagues and even strangers, covered many topics, both personal and professional, ranging from daily life during the Manhattan Project to the space shuttle Challenger investigation to advice to a high school student. Feynman's full personality shined through the colloquial prose of the was deemed safe and effective. The Mold in Dr. Florey's Coat (Henry Holt, paperback version published in 2005) salutes the contribution of Howard Florey, Ernest Chain and Norman Heatley, a team of Oxford University scientists who developed penicillin on a shoestring budget in wartime England. The book describes the ingenuity and improvisation that were necessary to build equipment to extract penicillin, the hardship of doing research under dangerous conditions, as well as the proposed strategy to preserve the mold spore by rubbing some into their clothing (thus the title of the book) in case they had to abandon work and flee from the threat of a Nazi invasion. Perhaps most importantly, the book gives credit to Heatley, who was left out of the 1945 Nobel Prize in physiology or medicine awarded for the development of penicillin. The Geneticists Who Play Hoops with My DNA (by David Ewing Duncan; HarperCollins) profiles seven contemporary influential biologists, each framed by a mythical or biblical figure (for example, Doug Melton as Prometheus or Cynthia Kenyon as Eve). While the idea is intriguing, it does run the risk of reducing each complex personality down to a caricature. Whether the chosen figures fit or not is a matter of personal opinion, of course. Nevertheless, the book is an easy read and is fun at times.

There are many more books about the life and work of well-known scientists than those listed here. So this summer, when packing bags for traveling, you might want to throw in a biography of one of your favorite scientists and learn what propels her or him to success. 